\title{
Pharmacological and non-pharmacological smoking motives: a replication and extension
}

\author{
JAMES C. TATE, CYNTHIA S. POMERLEAU \& \\ OVIDE F. POMERLEAU
}

University of Michigan Behavioral Medicine Program, Ann Arbor, Michigan, USA

\begin{abstract}
Cigarette smokers $(\mathrm{n}=387)$ completed a questionnaire measure of smoking motives, and subgroups of this sample provided extemal validation information. Seven factors emerged from a principal components' analysis: automatic, sedarive, addictive, stimulation, psychosocial, indulgent and sensorimotor manipulation. A higher-order principal components analysis revealed the presence of two second-order factors. Inspection of the pattern of correlations between factor scores and criterion variables clearly indicated that the first four factors above and their underlying second-order factor are more closely related to nicotine phamacology and mood-altering effects of nicotine than the latter three motives and their underlying second-order factor. Moreover, the positive correlations between these pharmacological motives and age, coupled with a negative relationship between age and the non-pharmacological motives, suppon the description of the smoking career as a progressive transfer of reward from non-pharmacological to phamacological factors. These findings suggest that self-reported reasons for smoking represent more than bias in verbal report.
\end{abstract}

\section{Introduction}

The question, "why do people smoke?" concisely summarizes the thrust of a large portion of cigarette smoking research conducted over the last three decades. A direct approach to answering this question is to ask smokers their reasons for smoking. Beginning in the mid-1960s, researchers began constructing questionnaires designed for this purpose and analyzing responses to these questionnaires to detect evidence of smoking motives. The development of reliable, valid self-report measures of smoking motives is important for both basic and applied reasons. Smoking motive scales would allow measurement of private events mediated by the proposed neuro-regulatory effects of nicotine

Correspondence to: Chris Tate, Ph.D., PO Box 87, Department of Psychology, Middle Tennessee State University, Murfreesboro, TN 37132 , USA.
(Pomerleau \& Pomerleau, 1984). Relating smoking motive scores to external criterion variables would help to separate pharmacological and non-pharmacological factors in cigarette smoking and further our understanding of smoking. Moreover, the identification of specific smoking motives could gujde the tailoring of smoking cessation treatment to the individual needs of patients (Kreitler, Shahar \& Kreitler, 1976).

Smoking motive questionnaires have been based on affect management models (Ikard, Green \& Horn, 1969), situations associated with smoking (McKennell, 1970; Best \& Hakstian, 1978) and arousal modulation models (Frith, 1971). Because the questionnaires used in these studies were not identical, different sets of smoking motives were found. Nevertheless, the large degree of content overlap resulted in the finding of similar sets of smoking motives, and the results of factor analytic studies demonstrate excellent consistency (Tate, Schmitz \& Stanton, 
1991). Different researchers labeled motives differently, but the following are representative names of the most commonly found motives: automatic (ATM), sedative (SED), addictive (ADD), stimulation (STM), psychosocial (SOC), indulgent (TND) and sensorimotor manipulation (SMM).

Russell, Peto \& Patel (1974) approached the question of smoking motives from the perspective of pharmacological versus non-pharmacological rewards of smoking. Using a 34-item questionnaire derived from both the Ikard et al. (1969) and McKennell \& Thomas (1970) measures, Russell et al. (1974) recovered six of the seven smoking motives (ATM, ADD, STM, SOC, IND \& SMM) and found evidence, via a higher-order factor analysis, of two more basic dimensions underlying these smoking motives. The first dimension, described as representing the pharmacological rewards of nicotine, was composed of the ATM, ADD and STM smoking motives. Although the expected SED factor did not emerge, these investigators suggest that it should load on the pharmacological dimension. The second, nonpharmacological dimension was composed of the SOC, IND and SMM smoking motives.

Russell et al. (1974) speculated that social and other non-pharmacological rewards motivate smoking initially and account for the stronger role of the SOC, IND and SMM motives early in the smoker's career. Eventually, the positive rewards of nicotine, due to its direct and indirect actions on the brain, exert more control as the smoker increasingly uses nicotine to modulate arousal and affective tone, thus accounting for the stronger role of the SED and STM motives as the smoker's career progresses. As nicotine intake increases and the pattern of intake becomes more regular, avoidance and relief of withdrawal become paramount, and the ATM and ADD motives becomes stronger. Thus, smokers progress along two orthogonal dimensions as they continue to smoke. Initially, non-pharmacological rewards exert greater conrool over smoking; however, pharmacological rewards develop greater control.

The validity of the pharmacological dimension was supported by moderate positive correlations (i.e., $r=0.50-0.63$ ) between STM, ADD, ATM and SED motive scores and smoking rate. Also, this dimension discriminated between a sample of nornal smokers not attempting to quit and a sample of addicted heavy smokers attending smoking cessation clinics. Specifically, clinic smokers scored higher on the pharmacological smoking motives. The non-pharmacological motives did not correlate as highly with smoking rate, and the SOC motive correlated negatively with age as predicted (Russell et al., 1974). Additional validation comes from three subsequent studies (Niaura et al., 1989; West, Hajek \& Belcher, 1986; West \& Russell, 1985) that demonstrated predicted relationships between pharmacological smoking motive scores and various criterion variables (i.e., withdrawal symptomatology, smoking rate, expired carbon monoxide, cotinine levels, etc.).

These studies lend support to the validity of Russell et al.'s (1974) pharmacological and nonpharmacological dimensions, but there are limitations. Limited sample sizes $(n=29-77)$ limit the reliability of the findings. Indeed, the correlation between ATM scores and smoking rate is the only consistent finding across the studies. Also, some results contrary to Russell et al.'s model emerged. Russell et al. (1974), West \& Russell (1985), and West et al. (1986) found that IND motive scores behaved more like those belonging to the pharmacological group (i.e., correlated positively with criterion variables). Similarly, Niaura et al. (1989) found significant positive correlations between IND and SMM scores and withdrawal and urge to smoke scores. Finally, in Russell et al. (1974), the ratio of subjects to questionnaire items used in making factor estimations (i.e., 5 to 1 ) is close to the minimum rule of thumb guide of 4 to 1 ( $\mathrm{Kim} \&$ Mueller, 1978). It is possible that this fact explains the failure to obtain an SED factor. Given that the stability of a factor solution increases as this ratio increases, replication in a large sample would increase confidence in this model of smoking behavior.

The general goal of this study was to examine the relationships between self-reports of smoking motives and external validation criteria in an attempt to establish the pharmacological underpinnings of specific reasons for smoking. As a first step towards demonstrating this, the following sub-goals were set and specific predictions made. First, we attempted to recover the first-order and second-onder factor structures described by Russell et al. (1974). Secondly, to establish the pharmacological and non-pharmacological natures of these factors, we investigated the rela- 
tionships between smoking motive scores and an array of pharmacological marker variables. We predicted that the ATM, SED, ADD, STM and the underlying second-order factor would correlate positively with plasma cotinine, smoking rate, length of time smoking, age and a questionnaire measure of nicotine dependence and negatively with latency to the first cigarette of the day. Also, we predicted that the SOC, IND, SMM and their underlying second-order factor would correlate negatively with age and minimally, of not at all, with the criterion measures. Thirdly, we predicted that a sub-sample of subjects recruited to participate in smoking cessation trials would have higher scores on the pharmacological motives and lower scores on the non-pharmacological motives as compared to a sub-sample of regular smokers not attempting smoking cessation. Finally, we predicted positive relationships between pharmacological motive scores and measures of trait anxiety and depression. It was reasoned that individuals reporting higher levels of subjective distress due to personality make up, negative environmental events or nicotine withdrawal would be more likely to report stronger pharmacological reasons for smoking.

\section{Method}

\section{Subjects}

Subjects were 387 cigarette smokers (179 females, 208 males) who participated in research projects carried out at the University of Michigan's Behavioral Medicine Program between 1986-1993. Two hundred and fifty-three of these subjects (106 females, 147 males) participated in laboratory projects, and 134 (73 females, 61 males) were participants in clinical trials involving smoking cessation. Laboratory subjects were chosen to be healthy, moderately dependent smokers and may not be representative of all smokers. Inclusion criteria for clinic subjects were somewhat less restrictive and specifically included a current desire to quit smoking.

\section{Measures}

Measures completed by most subjects included a smoking history form, the Fagerstrom Tolerance Questionnaire (FTQ; Fagerstrom, 1978), trait anxiety (STAI-Trait; Spielberger, Gorsuch \&
Lushene, 1970) and depression (CES-D; Weissman et al., 1977) measures, and a modified version of the Russell $e t$ al. (1974) smoking motives questionnaire (SMQ; Pomerleau et al., 1992). The modified SMQ was constructed by examining the factor structure reported in Russell et al. (1974) and, for each factor, selecting the three items with the highest significant (i.e., $\geqslant 0.40$ ) loadings in conjunction with nonsignificant loadings on the other factors. Only two such items could be found for the ATM and SED motives; consequently, a third item was rationally constructed for each of these scales. Appendix A contains the resulting scales. Responses to items are made on a 0 (not at all) to 3 (very much so) scale. Additionally, 297 subjects supplied plasma samples which were assayed for cotinine concentration via ether high-pressure liquid chromatography (Hariharan, Van Noord \& Greden, 1988) or gas chromatography Jacob, Wilson \& Benowitz, 1981). Due to changes in study demands and missing data, criterion variables data were in some instances available for only subsets of the database.

\section{Procedure}

Questionnaire materials were provided at a screening session and subjects completed these prior to actual involvement in a study. Data were inspected for completeness and entered into the database. Plasma samples were obtained prior to any experimental manipulations or provision of treatment. In some cases, these samples were collected after overnight smoking abstinence.

\section{Results}

\section{Subjects}

Table 1 shows descriptive data on the total sample, by sex, and laboratory/clinic subgroups. Generally, subjects were young, moderate smokers who reported smoking for an average of 16 years and being moderately dependent on nicotine. Univariate analyses of variance (ANOVA) testing for sex differences on these variables were non-significant with the exception of plasma cotinine concentration $[F(1$, 295) $=5.20, p=0.023$ ) with males having the higher concentration. Clinic and laboratory samples differed significantly on age $[F(1$, $385)=236.87]$, years smoked $[F \quad(1$, 
Table 1. Subject characteristics

\begin{tabular}{lccccc}
\hline Variable & Males & Females & Lab. & Clinic & Total \\
\hline Age (yrs) & & & & & \\
Mean & 32.84 & 32.80 & 28.86 & 40.31 & 32.82 \\
SD & $(9.10)$ & $(8.88)$ & $(6.38)$ & $(7.95)$ & $(8.84)$ \\
$n$ & 208 & 179 & 253 & 134 & 387 \\
Plasma cotinine (ng/m) & & & & & \\
Mean & 281.67 & 250.12 & 240.95 & 306.92 & 268.71 \\
SD & $(124.22)$ & $(106.56)$ & $(120.25)$ & $(104.05)$ & $(118.13)$ \\
$n$ & 175 & 122 & 172 & 125 & 297 \\
Smoking rate (cigs/day) & & & & & \\
Mean & 27.48 & 25.83 & 23.55 & 32.54 & 26.71 \\
SD & $(11.99)$ & $(8.38)$ & $(7.57)$ & $(12.44)$ & $(10.47)$ \\
$n$ & 203 & 179 & 248 & 134 & 382 \\
Years smoked & & & & & \\
Mean & 16.65 & 17.16 & 13.00 & 22.99 & 16.88 \\
SD & $(9.06)$ & $(8.32)$ & $(6.71)$ & $(8.02)$ & $(8.72)$ \\
$n$ & 189 & 154 & 210 & 133 & 343 \\
FTQ & & & & & \\
Mean & 7.23 & 7.32 & 6.88 & 7.76 & 7.27 \\
SD & $(1.69)$ & $(1.74)$ & $(1.80)$ & $(1.44)$ & $(1.71)$ \\
$n$ & 165 & 158 & 244 & 99 & 323 \\
Latency* (min) & & & & \\
Mean & 24.04 & 28.48 & 25.80 & - & - \\
SD & 31.85 & 27.35 & 30.84 & - & - \\
$n$ & 73 & 48 & 121 & - & - \\
\hline
\end{tabular}

* Data available for laboratory subjects only.

$341)=151.67], \quad$ smoking rate $\quad[F(1$, $267)=76.92], \quad$ plasma cotinine $\quad[F(1$, $295)=24.36]$, and FTQ $[F(1,321)=18.31]$ (all $p=0.0001$ ). Clinic subjects had higher values on all of these variables.

\section{Factor analysis}

First-order analysis. Responses to the $21 \mathrm{SMQ}$ items were entered into a principal components analysis. Using Kaiser's (1974) criterion (eigenvalues $\geqslant 1$ ) to determine how many factors to retain, a clear seven-factor solution, accounting for $65 \%$ of the total variance, emerged. The seven factors each accounted for $23,10,9,7,6$, 5 and $5 \%$ of the total variance, respectively. Following factor extraction, initial rotation was achieved via the varimax method, and rotation to a terminal solution was achieved via the oblique promax method.

Table 2 shows the factor loadings greater than 0.40 after rotation, communalities $\left(h^{2}\right)$, and Kaiser's Measure of Sampling Adequacy (MSA; Kaiser, 1970, 1974). Comparison of Table 2 and Appendix $A$ indicates that items loaded mainly on only one factor and the predicted pattern of factor loadings was obtained. Only six of 147 factor loadings were contrary to predictions to a significant degree. Two factors (ATM, IND) emerged exactly as predicted, and the SED and SMM factors emerged with an additional item loading significantly on each. For each of the SOC, ADD and STM scales, two of the three items behaved as predicted.

Kaiser's (1970, 1974) MSAs were calculated for each item and overall. This statistic is a measure of the degree to which the variance in each variable is accounted for by common factors, that is, the level of factorial determination (Kim \& Mueller, 1978). The MSA can vary between 0 and 1 , with higher values indicating greater factorial determination and empirical confirmation of a given factor solution. The last column of Table 2 contains MSAs for individual items. The overall MSA is 0.77 . Using Kaiser's guidelines for interpretation, these values are quite acceptable and support the appropriateness of the seven-factor solution.

Second-order analysis. Inspection of the correlation matrix in Table 3 reveals moderate inter-correlations among the seven factors with 
Table 2. Factor loading ${ }^{\star}$ from first-order factor analysis

\begin{tabular}{|c|c|c|c|c|c|c|c|c|c|}
\hline \multirow[b]{2}{*}{ Item } & \multicolumn{7}{|c|}{ Factor } & \multirow[b]{2}{*}{$h^{2}$} & \multirow[b]{2}{*}{ MSA } \\
\hline & ATM & SED & SOC & IND & ADD & SMM & STM & & \\
\hline 3 & 0.91 & & & & & & & 0.81 & 0.67 \\
\hline 1 & 0.84 & & & & & & & 0.71 & 0.75 \\
\hline 2 & 0.78 & & & & & & & 0.64 & 0.81 \\
\hline 4 & & 0.76 & & & & & & 0.61 & 0.84 \\
\hline 6 & & 0.69 & & & & & & 0.64 & 0.83 \\
\hline 5 & & 0.69 & & & & & & 0.64 & 0.84 \\
\hline 9 & & $0.67 \dagger$ & & & $-0.46 t$ & & & 0.64 & 0.81 \\
\hline 8 & & & 0.81 & & & & & 0.70 & 0.75 \\
\hline 7 & & & 0.81 & & & & & 0.76 & 0.77 \\
\hline 20 & & & $0.54 \dagger$ & & $0.44 t$ & & & 0.55 & 0.87 \\
\hline 11 & & & & 0.84 & & & & 0.70 & 0.61 \\
\hline 10 & & & & 0.84 & & & & 0.70 & 0.60 \\
\hline 12 & & & & 0.53 & & & & 0.46 & 0.73 \\
\hline 15 & & & & & 0.77 & & & 0.63 & 0.77 \\
\hline 13 & & & & & 0.74 & & & 0.65 & 0.84 \\
\hline 16 & & & & & & 0.84 & & 0.71 & 0.66 \\
\hline 14 & & & & & & 0.53 & & 0.59 & 0.82 \\
\hline 17 & & & & & & $0.52 \dagger$ & & 0.57 & 0.63 \\
\hline 18 & & & $0.40 \dagger$ & & & 0.44 & & 0.58 & 0.67 \\
\hline 19 & & & & & & & 0.87 & 0.74 & 0.71 \\
\hline 21 & & & & & & & 0.68 & 0.66 & 0.80 \\
\hline
\end{tabular}

* Standardized regression coefficients. Loadings $<0.40$ not shown. $\dagger$ Loadings contrary to predictions.

coefficients ranging from -0.05 to 0.37 . Consequently, the seven factors were arranged such that more highly correlated factors are adjacent, forming two groups of intercorrelated factors. This prompted a second-order principal components analysis. Two second-order factors, respectively accounting for $28 \%$ and $18 \%$ of the total variance, emerged using Kaiser's criterion to terminate factor extraction. Rotation to simple structure was achieved initially via the varimax method and terminally via the promax method. Table 4 contains the seven first-order factors and their loadings on the two second-order factors. The two second-order factors demonstrated a low inter-correlation $(r=0.15)$.

\section{Validity}

Table 5 contains correlations between factor scores and criterion variables. Five of these variables relate directly to cigarette consumption, nicotine intake and nicotine dependence (plasma cotinine, smoking rate, years smoked, FTQ, latency to the first cigarette of the day). Age was included because Russell et al. (1974) postulated a positive relationship between age and strength of the pharmacological rewards of smoking and a negative relationship between age and the strength of the non-pharmacological rewards of smoking. Due to the large number of correlations, minimum significance was set at $p \leqslant 0.01$.

Factor I, ATM and ADD scores correlated as predicted with all criterion variables. The STM scores correlated as predicted with four of six criterion variables, and SED scores correlated with number of years smoking. With the exception of a significant positive correlation between SOC scores and smoking rate, none of the correlations involving the SOC, IND, SMM and Factor II scores were significant. There was, however, a trend $(p<0.05)$ for IND and Factor II scores to correlate negatively with age. Focusing only on the correlations between second-order factor scores and criterion variables, Student's $t$-statistic was computed to test whether differences between correlation coefficients are significant. In every case, the difference was significant. Correlations between Factor I and pharmacological marker variables are significantly larger than comparable correlations involving Factor II.

Next, motive factor scores for the clinic and 
Table 3. Inter-factor correlations

\begin{tabular}{lrrrrrrr}
\hline & ATM & SED & ADD & STM & SOC & IND & SMM \\
\hline ATM & 1.00 & & & & & & \\
SED & 0.25 & $\mathbf{1 . 0 0}$ & & & & & \\
ADD & 0.25 & 0.37 & 1.00 & & & & \\
STM & 0.23 & 0.14 & 0.23 & 1.00 & & & \\
SOC & 0.19 & 0.24 & 0.07 & 0.20 & 1.00 & & \\
IND & 0.00 & -0.05 & 0.00 & -0.02 & 0.22 & 1.00 & \\
SMM & 0.25 & 0.07 & 0.05 & 0.08 & 0.20 & 0.07 & 1.00 \\
\hline
\end{tabular}

laboratory sub-samples were compared using univariate ANOVAs. Significant results were obtained for the STM $[F(1,385)=27.81$, $p=0.0001], \quad$ ADD $\quad[F(1, \quad 385)=88.62$, $p=0.0001], \quad$ SED $\quad[F(1,385)=25.09$, $p=0.0001], \operatorname{ND}[F(1,385)=7.08, p=0.008]$ and $\operatorname{SMM}[F(1,385)=4.04, p=0.045] \mathrm{mo-}$ tives. Clinic subjects had higher STM, ADD, SED and IND scores and lower SMM scores than the laboratory sub-sample. This analysis was repeated with the second-order factor scores as dependent variables, and similar results were obtained. Clinic subjects had higher Factor I scores $[F(1,385)=73.49, p=0.0001]$. The ANOVA involving Factor Il scores was nonsignificant $[F(1,385)=0.06, p=0.81]$.

To assess further the validity of the smoking motive factors, factor scores were correlated with measures of trait anxiety and depression (see Table 6). The SED, ADD, Factor I scores correlated significantly with STAI scores. The SED scores correlated with CES-D scores also. Contrary to predictions, SOC scores correlated significantly with STAI scores.

Table 4. Factor loadings* from the secondorder factor analysis

\begin{tabular}{lrc} 
& \multicolumn{2}{c}{ Second-order factors } \\
\cline { 2 - 3 } $\begin{array}{l}\text { First-order } \\
\text { factors }\end{array}$ & Factor I & Factor II \\
\hline ADD & 0.73 & -0.15 \\
SED & 0.70 & -0.02 \\
ATM & 0.61 & 0.13 \\
STM & 0.53 & 0.10 \\
SOC & 0.23 & 0.71 \\
IND & -0.25 & 0.69 \\
SMM & 0.09 & 0.58 \\
\hline
\end{tabular}

* Standardized regression coefficients.

\section{Discussion}

The goal of this study, to examine smoking motives systematically in a larger population, were largely met. The findings replicate and extend the results of previous investigations of self-reported smoking motives and their relationships to nicotine pharmacology. Seven smoking motives were identified by factor analysis, and a second-order factor analysis revealed the presence of two more basic dimensions. These firstand second-order factors are strikingly similar to those obtained by Russell et al. (1974) in terms of item composition, inter-factor correlations and variance accounted for. However, we found a much clearer separation between the secondorder factors as evidenced by the unequivocal pattern of second-order factor loadings and the low inter-factor correlation. In addition, predicted relationships between smoking motive factor scores and external criterion variables were observed.

Correlations between most of these dimensions and pharmacological markers demonstrated predicted patterns, thus lending credence to the pharmacological and non-pharmacological labels applied by Russell et al. (1974). Factor I clearly seems more pharmacological in nature than Factor II. Furthermore, STM, SMM, ADD, SED and Factor I scores discriminated between a group of heavy, addicted smokers seeking smoking cessation treatment and a group of less dependent smokers. Lastly, subjects with higher SED scores reported being generally more anxious and depressed, subjects with higher ADD scores reported being more anxious, and subjects with higher Factor I scores reported being more anxious. These results imply that smokers who experience more subjective distress may derive greater reinforcement and/or relief of dysphoric states from smoking. 
Table 5. Correlations between factor scores and criterion variables

\begin{tabular}{lcccccc}
\hline Factor & $\begin{array}{c}\text { Plasma } \\
\text { cotinine } \\
(n=297)\end{array}$ & $\begin{array}{c}\text { Smoking } \\
\text { rate } \\
(n=382)\end{array}$ & $\begin{array}{c}\text { Years } \\
\text { smoked } \\
(n=343)\end{array}$ & $\begin{array}{c}\text { Age } \\
(n=387)\end{array}$ & $\begin{array}{c}\text { FTQ } \\
(n=323)\end{array}$ & $\begin{array}{c}\text { Latency } \\
(n=121)\end{array}$ \\
\hline ATM & $0.24^{\star \star \star}$ & $0.48^{\star \star \star}$ & $0.33^{\star \star \star}$ & $0.29^{\star \star \star}$ & $0.27^{\star \star \star}$ & $-0.28^{\star}$ \\
SED & -0.03 & 0.09 & $0.14^{\star}$ & 0.07 & 0.12 & -0.10 \\
ADD & $0.21^{\star \star}$ & $0.39^{\star \star \star}$ & $0.34^{\star \star \star}$ & $0.32^{\star \star}$ & $0.33^{\star \star \star}$ & $-0.28^{\star}$ \\
STM & 0.11 & $0.28^{\star \star \star}$ & $0.25^{\star \star \star}$ & $0.24^{\star \star \star}$ & $0.16^{\star}$ & -0.02 \\
Factor I & $0.20^{\star \star}$ & $0.47^{\star \star \star}$ & $0.40^{\star \star \star}$ & $0.35^{\star \star \star}$ & $0.33^{\star \star \star}$ & $-0.24^{\star}$ \\
SOC & -0.04 & $0.15^{\star}$ & 0.01 & -0.01 & 0.14 & -0.10 \\
IND & -0.01 & -0.08 & -0.07 & -0.11 & 0.10 & -0.04 \\
SMM & -0.10 & 0.12 & -0.10 & -0.09 & -0.07 & 0.10 \\
Factor II & -0.08 & 0.09 & -0.08 & -0.10 & 0.09 & -0.02 \\
$t$ & $3.96^{\star \star}$ & $6.43^{\star \star}$ & $7.60^{\star \star}$ & $7.33^{\star \star}$ & $3.57^{\star \star}$ & $3.99^{\star \star}$ \\
\hline
\end{tabular}

${ }^{\star} p<0.01,{ }^{\star \star} p<0.001,{ }^{\star \star \star} p<0.0001$.

Not all results were as predicted. Clinic subjects had higher IND scores than laboratory subjects. Otherwise, IND scores behaved as if non-pharmacologically based. This motive, originally postulated as straddling the pharmacological/non-pharmacological dimension, was found by Russell et al. (1974) to load on a non-pharmacological second-order factor and to correlate significantly with daily smoking rate, a seemingly paradoxical finding. West et al. (1986) and West \& Russell (1985) reported significant positive correlations between IND scores and pharmacological marker variables. Thus, there is precedent for ambiguity concerning the IND smoking motive, and further research will be needed to clarify the nature of this motive.

Also, the non-pharmacological SOC motive correlated with smoking rate and trait anxiety scores. It is possible that some anxious individu-

Table 6. Relationships between smoking motive factor scores, trait anxiety and depression

\begin{tabular}{lcc} 
Factor & $\begin{array}{c}\text { Trait anxiety } \\
(n=372)\end{array}$ & $\begin{array}{c}\text { Depression } \\
(n=200)\end{array}$ \\
\hline ATM & 0.05 & 0.07 \\
SED & $0.16^{\star}$ & $0.25^{\star \star}$ \\
ADD & $0.14^{\star}$ & 0.06 \\
STM & 0.03 & -0.07 \\
Factor 1 & $0.14^{\star}$ & 0.13 \\
SOC & $0.16^{\star}$ & 0.06 \\
IND & -0.09 & -0.05 \\
SMM & 0.09 & -0.03 \\
Factor II & 0.07 & -0.005 \\
\hline
\end{tabular}

${ }^{\star} p<0.01,{ }^{\star \star} p<0.001$. als score highly on the SOC motive because they experience heightened anxiety when in social situations, and the act of smoking may represent a pharmacological coping device (Pomerleau \& Pomerleau, 1984). Two pieces of evidence support this interpretation. First, the two items loading highest on the SOC factor (items 10, 14) contain content suggesting increased ease and confidence via smoking in social situations. This is conceptually similar to the avoidance or reduction of negative affect central to the concept of SED smoking. Secondly, the SOC and SED motives are correlated significantly in this sample (see Table 3). Although plausible, the present correlational design cannot settle the issue.

Finally, the SED factor's showing was not as consistent or as strong as expected. The SED scores correlated as predicted with number of years smoked, trait anxiety and depression; demonstrated a marginal trend with respect to FTQ scores and latency to the first cigarette of the day; but were unrelated to plasma cotinine, smoking rate and age. Russell et al. (1974) failed to find evidence of an SED factor. As with the IND factor, there is precedent for inconsistency, and further research may shed light on the matter.

These findings have several implications. First, individuals who report smoking to increase/decrease arousal or because of habit or addiction are likely to be using nicotine for its pharmacological effects. Thus, the stimulatory and sedative functions of smoking are probably mediated by nicotine. Moreover, the automaticity of smoking may serve to maintain nicotine levels above a certain threshold, thus preventing with- 
drawal. When abstinence is unavoidable, discomfort and craving motivate drug seeking. Although the present study does not represent a direct test of these assertions, the general finding that the ATM, SED, ADD and STM smoking motives are more strongly related to external validation criteria than the SOC, IND and SMM motives is consistent with the view of smoking being motivated by both the mood-altering effects of nicotine and avoidance/relief of nicotine withdrawal (Pomerleau \& Pomerleau, 1984). The positive correlations between SED and Factor I scores and mood and anxiety further support this interpretation.

Secondly, positive correlations between pharmacological factors and length of time smoking and age support the description of the smoking career as a progressive transfer of reward and control from predominantly non-pharmacological to predominantly pharmacological factors. A longitudinal design would be needed to support this interpretation unequivocally, but the current data show small to moderate significant relationships in precicted directions and are consistent with the development of increasing tolerance to nicotine as a function of years of smoking described elsewhere (Henningfield \& Nemeth-Coslett, 1988). Stronger negative relationships between age and the nonpharmacological factors might have been obtained if younger smokers (age $<18 \mathrm{yrs}$ ) were included in the sample. Russell et al. (1974) recruited subjects as young as 16 years of age and obtained a correlation between age and SOC scores of -0.23 . More recent support for this interpretation comes from a longitudinal study by Stanton et al. (1993) in which reasons for smoking were assessed in a cohort of children at ages 11 and 13 years. They found that the importance of "image" smoking ("I look better with a cigarette in my hand") declined significantly during the intervening two years, and smoking because of "friends" ("I smoke because I don't want to be the odd one out in a group") demonstrated a statistically significant, but small, degree of consistency. Possibly, the rapidity with which people become nicotine dependent renders psychosocial motives less important in a similarly rapid fashion.

A review of the RFS (Tate et al., 1991) documented that groups of smokers report remarkably similar motives with excellent consistency; however, analogue, self-monitoring and treatment studies support neither the validity nor clinical utility of the individual motive scales. Although the literature is fraught with methodological problems, this finding raises the issue of the relationship between self-reported smoking motives and actual smoking behavior. Schachter (1978) argued that the "psychological and probably the sensory and manipulative gratifications of smoking are illusory" (p. 112). Because the RFS and SMQ share item content, this issue is relevant to the SMQ. The results presented here demonstrate clearly that some smoking motives have stronger pharmacological ties than other motives. Consequently, motive scores represent more than self-report bias. Nevertheless, the specific nature of these ties remains speculative.

Consequently, the answer to the question of why people smoke continues to be elusive. A partial reason for the difficulty may be that nicotine is a drug with multiple pharmacological properties and that the tenacity of cigarette smoking is based upon the diversity of nicotine's actions (Pomerleau \& Pomerleau, 1984). In view of the apparent ability of smokers to secure a wide range of effects, with reinforcement value modulated by ongoing activities and environmental context, a productive use of the findings of motives-for-smoking research might be to provide guidance for systematic investigations of the circumstances that trigger smoking and the subjective, behavioral, physiological and neuroendocrine consequences of nicotine selfadministration. Such research may resolve some of the contradictions and ambiguities of the initial attempts to classify smokers and, ultimately, should lead to a better understanding of nicotine dependence and cigarette smoking.

\section{Acknowledgements}

Preparation of this manuscript was supported by National Institute on Drug Abuse Grant DA 06529 and by National Cancer Institute Grant CA 42730 to the third author. The authors are grateful to Samuel B. Green and Mary Lutzke for their valuable assistance. Correlation matrices are available from the first author.

\section{References}

BEST, A. I. \& HAKSTIAN, A. R. (1978) A situationspecific model for smoking behavior, Addictive Behaviors, 3, pp. 79-92. 
Fagerstrom, K. O. (1978) Measuring degree of physical dependence to tobacco smoking with reference to individualization of treatment, Addictive Behaviours, 3, pp. 235-241.

FRrTH, C. D. (1971) Smoking behaviour and its relation to the smoker's immediate experience, British foumal of Social and Clinical Psychology, 10, pp. 73-78.

HARIHAN, M., VANNOORD, T. \& GREDEN, J. F. (19.88) A high-performance liquid-chromatographic method for routine simultaneous determination of nicotine and cotinine in plasma, Clinical Chemistry, 34, pp. $724-729$.

Hennargfield, J. E. \& Nemeth-Cosintt, R. (1988) Nicotine dependence: interface between tocacco and tobacco-related disease, Chest (Supplement), 93, pp. $37 S-55 S$.

IkARD, F. F., GRFEN, D. E. \& Hown, D. (1969) A scale to differentiate between types of smoking as related to the management of affect, Intemational Foumal of the Addictions, 4, pp. 629-639.

JACOB, P., WIISON, M. \& BENOWITZ, N. L. (1981) Improved gas chromatographic method for the determination of nicotine and cotinine in biologic fluids, foumal of Chromatography, 222, pp. 61-70.

KAISER, H. F. (1970) A second-generation little jiffy, Psychometrika, 35, pp. 401-415.

KAISER, H. F. (1974) An index of factorial simplicity, Pychometrika, 39, pp. 31-36.

KIM, J. \& MUEller, C. W. (1978) Factor Anatysis: Statistical Methods and Practical Issues (Beverly Hills, Sage).

Kreitler, S., Shahar, A. \& Kreitler, H. (1976) Cognitive orientation, type of smoker and behaviour therapy of smoking, British foumal of Medical Psychology, 49, pp. 167-175.

MCKENNELL, A. C. (1970) Smoking motivation factors, British Foumal of Social and Clinical Psychology, 9, pp. 8-22.

Niaura, R., Goldostein, M. G., Ward, K. D. \& Agrams, D. B. (1989) Reasons for smoking and severity of residual nicotine withdrawal symptoms when using nicotine chewing gum, British foumal of Addiction, 84, pp. 681-687

Pomerleau, O. F. \& Pomerleau, C. S. (1984) Neuroregulators and the reinforcement of smoking: towards a biobehavioral explanation, Neuroscience $\sigma$ Biobehavioral Reviews, 8, pp. 503-513.

Pomerleat, C. S., Pomerleau, O. F., Flessland, K. A. \& Basson, S. M. (1992) Relationship of tridimensional personality questionnaire scores and smoking variables in female and male smokers, Fournal of Substance Abuse, 4, pp. 143-154.

Russell, M. A. H., PeTO, J. \& PATEL, U. A. (1974) The classification of smoking by factorial structure of motives, Foumal of the Royal Statistical Saciety, $A$, 137 , pp. 313-342.

SCHACHTER, S. (1978) Pharmacological and psychological determinants of smoking, Annais of Intemal Medicine, 88, pp. 104-114.

SPIELberger, C. D., Gorsuch, R. L. \& LusheNe, R. E. (1970) Manual for the State Trait Anxiety Inventory (Palo AJto, CA, Counseling Psychologists Press).
Stanton, W. R, Mahalask, P. A., McGee, R. \& SILVA, P. A. (1993) Rersons for smoking or not smoking in early adolescence, Addictive Behavions, 18, pp. 321-329.

TATE, J. C., Schmitz, J. M. \& STanton, A. L. (1991) A critical review of the reasons for smoking scale, fourmal of Substance Abuse, 3, pp. 441-455.

Weissman, M. M., Sholomakis, D., Pottenger, M. PruShOFF, B. A. \& LOCKE, B. Z. (1977) Assessing depressive symptoms in five psychiatric populations: A validation study, American Foumal of Epidemiology, 106, pp. 203-214.

West, R. J., HAJEK, P. \& BELChER, M. (1986) Which smokers report most relief from craving when using nicotine chewing gum, Psychophamacology, 89, pp. 189-191.

WEST, R. J. \& Russel., M. A. H. (1985) Pre-abstinence smoke intake and smoking motivation as predictors of severity of cigarette withdrawal symptoms, Psychopharmacology, 87, pp. 334-336.

\section{APPENDIX I}

\section{Modified smoking motives questionnaire}

ATM

1. I've found a cigarette in my mouth without recalling putting it there.

2. I light up a cigarette without realizing I still have one buming in the ashtray.

3. I find myself smoking withour remembering lighting up.

\section{SED}

4. I smoke more when I am worried about something.

5. Smoking calms me down when I fell tense.

6. I light up a cigarette when I feel angry about something.

SOC

7. It is easier to talk and get on with other people when smoking.

8. While smoking I feel more confident with other people.

9. I smoke much more when I am with other people.

\section{IND}

10. I want to smoke most when I am comfortable and relaxed.

11. I like a cigarette best when I am having a quiet rest.

12. I usually only smoke when I can really sit back and enjoy it.

\section{ADD}

13. When I have run out of cigarettes I find it almost unbearable until I can get them.

14. Without a cigarette I don't know what to do with my hands.

15. I get a real gnawing hunger to smoke when 1 haven't smoked for a while. 
SMM

16. I smoke for the pleasure of having something to put in my mouth.

17. Part of the enjoyment of smoking is watching the smoke as I blow it out.

18. Part of the enjoyment of smoking comes from the steps I take to light up.
STM

19. I like smoking while I am busy and working hard.

20. I get a definite lift and feel more alert when smoking.

21. I smoke more when I am rushed and have lots to do. 
This document is a scanned copy of a printed document. No warranty is given about the accuracy of the copy. Users should refer to the original published version of the material. 